\title{
Combination-Sensitive Neurons in the Primary Auditory Cortex of the Mustached Bat
}

\author{
Douglas C. Fitzpatrick, Jagmeet S. Kanwal, John A. Butman, and Nobuo Suga \\ Department of Biology, Washington University, St. Louis, Missouri 63130
}

In the mustached bat, Pteronotus parnellii, neurons in the primary auditory cortex (Al) have been thought to respond primarily to single frequencies, as in other mammals. However, neurons in the Doppler-shifted constant-frequency (DSCF) area, a part of the mustached bat's Al that contains an overrepresentation of the prominent $\mathrm{CF}_{2}$ component of the biosonar signal, were found to show facilitative responses to combinations of different frequencies in the pulse and echo. The essential components for facilitation were the pulse $F M_{1}$ and the echo $C F_{2}$. The $F M_{1}-C_{2}$ facilitation was sensitive to echo delays, indicating that DSCF neurons respond better to targets within particular ranges. On average, the longest discriminable echo delay, based on increased impulse counts due to facilitation, corresponded to a target range of $4.3 \mathrm{~m}$, and the most discriminable delay corresponded to a target $3.6 \mathrm{~m}$ distant. Since mustached bats first show a behavioral response to a target at a distance of 3-4 m, DSCF neurons are suited to signal the presence of an insect within this behaviorally important range. DSCF neurons were broadly tuned to echo delay, with the the average minimum discriminable echo delay corresponding to a target range of $1.9 \mathrm{~m}$, and the delay tuning of the neurons followed (tracked) changes in pulse duration, indicating that facilitation occurs during much of the approach phase of insect pursuit when target characterization is presumably occurring. These results show that $A$ l neurons in the mustached bat are speciatized to respond to complex, behaviorally relevant stimuli during the search and approach phases of insect pursuit.

IKey words: biosonar, echolocation, neuroethology, cerebral cortex, auditory system, facilitation, overrepresentation]

In bat biosonar, accurate estimation of information-bearing parameters such as echo delay (for measuring the distance to objects) and amount of Doppler shift (for measuring relative target velocity) are critical for successful foraging. The auditory cortex of the mustached bat, Pteronotus parnellii, contains multiple

\footnotetext{
Received July 7, 1992; revised Aug. 27, 1992; accepted Sept. 1, 1992.

This work was supported by a fellowship from the McDonnell Center for the Study of Higher Brain Function to D.C.F., by NIH Grant NS07057-12 to J.S.K., and by NIDCD Grant DC00175, ONR Grant 00014-90-J-1068, and a McKnight Foundation award to N.S. We thank Ari Berkowitz and Drs. Harold Burton and Kevin Ohlemiller for comments on the manuscript.

Correspondence should be addressed to N. Suga, Department of Biology, Box 1137, Washington University, St. Louis, MO 63130.

Copyright (C) 1993 Society for Neuroscience $0270-6474 / 93 / 130931-10 \$ 05.00 / 0$
}

areas specialized for extracting different information-bearing parameters from biosonar signals (Fig. $1 A$ ). The FM-FM area, for example, contains neurons tuned to particular echo delays that are systematically arrayed across the area (Suga and O'Neill, 1979; O'Neill and Suga, 1982; Suga et al., 1983b). Similarly, the $\mathrm{CF} / \mathrm{CF}$ area contains neurons tuned to particular Doppler shifts, and the amount of Doppler shift is systematically expressed on the cortical surface (Suga et al., 1983). FM-FM and $\mathrm{CF} / \mathrm{CF}$ neurons are combination sensitive, in that they respond poorly to single tones and single elements in the biosonar signal, but are facilitated by combinations of two signal elements.

The primary auditory cortex (AI) of mustached bats contains an cxpanded representation of a behaviorally significant frequency band, about $60-64 \mathrm{kHz}$, that corresponds to the secondharmonic constant-frequency component $\left(\mathrm{CF}_{2}\right)$ of the biosonar signal (Fig. $1 B$ ). While flying, mustached bats lower the frequency of the emitted pulse to compensate for Doppler shifts in echoes, so that the "Doppler shift-compensated" echo $\mathrm{CF}_{2}$ is stabilized to a frequency (called the reference frequency) that is typically between about 61.0 and $61.5 \mathrm{kHz}$ (Schnitzler, $1970 a, b)$. An overrepresentation of this important frequency band begins at the periphery and is maintained throughout the auditory system (Pollack et al., 1972; Suga et al., 1975; Suga and Jen, 1976; Pollack and Bodenhamer 1981; Kossl and Vater, 1985; Olsen, 1986; Zook and Leake, 1989; Covey et al., 1991). In the auditory cortex, the area containing the overrepresentation of the echo $\mathrm{CF}_{2}$ is called the Doppler-shifted CF (DSCF) processing area.

Within the mustached bat auditory cortex, there is a main tonotopic representation (Fig. $1 A$ ) that receives topographic projections from the ventral division of the medial geniculate body (MGB), and is therefore presumably homologous to AI of other species (Suga and Jen, 1976; Olsen, 1986). The DSCF area occupies approximately $50 \%$ of the mustached bat's AI. In other species, a large proportion of AI neurons respond well to pure tones and have a single characteristic frequency to which they respond at lowest threshold (see Brugge, 1985, for a review). This is also true of mustached bat AI neurons, including those in the DSCF area (Suga and Jen, 1976; Suga, 1977; Manabe et al., 1978; Suga and Manabe, 1982; Suga et al., 1987). However, we noticed that in addition to the well-characterized response to the $\mathrm{CF}_{2}$, DSCF neurons are facilitated when the $\mathrm{CF}_{2}$ is paired with frequencies contained in the first harmonic of the biosonar signal $\left(\mathrm{H}_{1}\right.$; see Fig. $\left.1 B\right)$. Here we describe this combination sensitivity and show that the facilitation is sensitive to echo delay, and hence to target range. This is the first report that demonstrates specialized responses of AI neurons to behaviorally relevant combinations of species-specific sounds. 

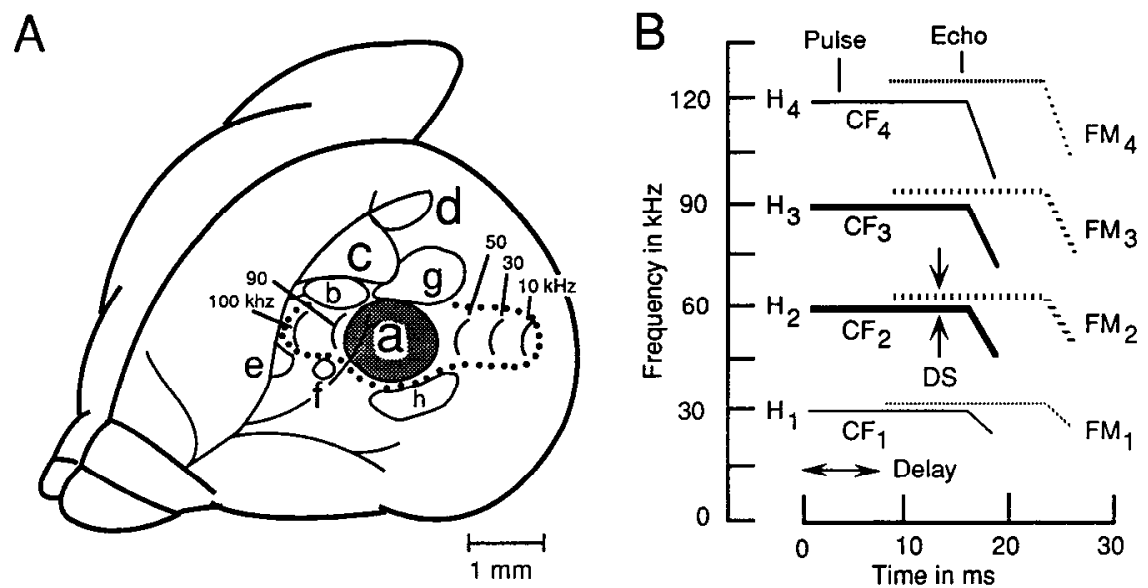

Figure 1. A, A dorsolateral view of the functional organization of the mustached bat's auditory cortex. The dots enclose the AI where low frequencies are represented posteriorly and high frequencies anteriorly. Within AI, area $a$ is the DSCF area, which overrepresents frequencies of $60-63 \mathrm{kHz}$. Area $b$ is the CF/CF area, which contains combination-sensitive neurons that encode target velocity. Areas $c, d$, and $e$ are the FM-FM, dorsal fringe (DF), and ventral fringe (VF) areas, respectively, that contain combination-sensitive neurons encoding target range. Area $f$ is the $\mathrm{H}_{1}$ $\mathrm{H}_{2}$ area, which contains neurons that respond to all combinations of the first and second harmonics of the biosonar signal. Areas $g$ and $h$ are the dorsomedial and ventroposterior areas, respectively, that contain neurons with multipeaked tuning curves that are sensitive to changes in sound locations. B, A schematized biosonar signal. The signal consists of an emitted pulse (solid lines) and echo (dotted lines). The pulse has four harmonics $\left(\mathrm{H}_{1}-\mathrm{H}_{4}\right)$ and each harmonic has a $\mathrm{CF}$ and an $\mathrm{FM}$ component $\left(\mathrm{CF}_{1-4}\right.$ and $\mathrm{FM}_{1-4}$, respectively). The echo is shown delayed and Doppler shifted (DS) from the pulse.

\section{Materials and Methods}

Surgery and recording of action potentials. Recordings were made in seven bats, using methods described previously (Suga et al., 1983b). Under Innovar analgesia $(0.08 \mathrm{mg} / \mathrm{kg}$ Fentanyl and $4 \mathrm{mg} / \mathrm{kg}$ Droperidol, i.m.) the skull was exposed and a metal post mounted with cyanoacrylate gel. Three days after surgery, the unanesthetized bat was placed in a styrofoam restraint suspended by an elastic band at the center of a soundproof, echo-attenuated room maintained at $30-32^{\circ} \mathrm{C}$. The head was immobilized by fixing the post mounted on the skull into a metal tube with set-screws, and adjusted so that the eye-nose line was centered at $0^{\circ}$ in front of condenser loudspeakers located $68 \mathrm{~cm}$ away. Insulated tungsten-wire electrodes with tip diameters of 5-10 $\mu \mathrm{m}$ were inserted into the DSCF area through small holes $(\sim 50 \mu \mathrm{m}$ diameter) made in the skull with a sharpened needle. An indifferent electrode was placed anterior or posterior to the auditory cortex. Ncuron activity was rccorded in the middle layers (300-600 $\mu \mathrm{m}$ depth). A window discriminator was used to isolate the responses of single neurons, and conditioned pulses from the discriminator were fed to a high-speed event recorder ( $\mathrm{MI}^{2}$, Philadelphia, $\left.\mathrm{PA}\right)$ for the recording of spike arrival times.

Acoustic stimuli. Synthesized components of biosonar pulses and echoes were delivered from separate condenser loudspeakers. Each pulse and each echo consisted of CFs followed by FMs or combinations of these. The durations of the CFs and FMs were 20 and $3.0 \mathrm{msec}$, respectively, except where otherwise noted. The frequency range swept by the $\mathrm{FM}_{1}$ was $6 \mathrm{kHz}$; the $\mathrm{FM}_{n} \mathrm{~s}(n=2,3$, or 4$)$ swept 12,18 , or 24 $\mathrm{kHz}$. The rise and decay times of the signals were $0.5 \mathrm{msec}$, and the stimuli were delivered at a rate of $5 / \mathrm{sec}$. Stimulus amplitudes were controlled with manual attenuators. All stimulus levels reported are in dB SPL (sound pressure level re $20 \mu \mathrm{Pa}$ ).

Stimuli for examining the echo delay sensitivity of neurons consisted of trains of pulse-echo pairs with decrementing echo delays, generated with computer-controlled pulse generators and timers $\left(\mathrm{MI}^{2}\right)$. The trains were $3450 \mathrm{msec}$ long and divided into 23 blocks, each of $150 \mathrm{msec}$ duration. Blocks 2-21 contained pulse and echo components that decremented in echo delay at the rate of $2.5 \mathrm{msec} / \mathrm{block}$, starting from 47.5 msec delay (block 2) to 0 msec delay (block 21). Blocks 1, 22, and 23 contained a pulse $\mathrm{H}_{1}$ alone, echo $\mathrm{H}_{2}$ alone, and no stimulus, respectively. The silent period between trains was $200 \mathrm{msec}$. Each stimulus within a train was presented at the best frequency and amplitude for facilitation.

Data collection and analysis. When action potentials of a single DSCF neuron were recorded, we first identified the best frequencies or best FMs, best amplitudes, and best dclay for facilitation, the minimum thresholds to each facilitatory component, and the upper threshold (if any) of each component. The frequency of the best FM was expressed by the initial frequency of the sweep. Stimuli presented at the the best frequencies and amplitudes for facilitation were called the best stimuli (e.g., best $\mathrm{CF}_{2}$ ). The best facilitative frequencies of each neuron were normalized to account for differences in the frequency of $\mathrm{CF}_{2}$ emitted while at rest among individual bats, according to the formula $y=x$ (61.00/RF), where $y$ is the normalized and $x$ the measured best frequency for facilitation, $\mathrm{RF}$ is the measured resting frequency, and $61.00 \mathrm{kHz}$ is taken as the approximate population mean for resting frequency. The methods used to measure RF were identical to those described in Suga et al. (1987).

Based on the recorded spike arrival times, we constructed peristimulus time histograms (PSTHs) and cumulative PSTHs, and determined latencies. Receiver operating characteristic (ROC) analysis was used to determine objectively whether different stimuli could be discriminated on the basis of impulse count. The probability distributions of impulse counts (i.e., the number of stimuli that yielded a given number of spikes divided by the total stimuli presented) were determined from the responses to 150 stimuli at each of 20 different echo delays. Responses were counted over a time window of $150 \mathrm{msec}$. Based on these impulse count distributions, ROC curves (see Fig. $5 \mathrm{~A}$ ) were constructed to estimate the discriminability of each delay from the longest delay tested $(47.5 \mathrm{msec})$, to which no facilitation was ever observed. To construct the ROC curves, the minimum impulse number (or criterion level) for deciding that the short delay occurred, the criterion level was varied from 0 to the maximum observed, and the probability of "hits" was plotted against the probability of "false alarms." A hit occurred when the impulse count exceeded the criterion level when the short delay stimulus was presented, and a false alarm occurred when the response to the long delay stimulus exceeded the criterion level. Thus, when the critcrion level was 0 impulses it was exceeded by all stimuli, and the probability of hits and false alarms was equal to 1 . When the shortdelay stimulus caused reliable facilitation and the criterion level was such that it was rarely exceeded in the absence of facilitation, then the probability of hits approached 1 while the probability of false alarms approached 0 . The probabilities of hits and false alarms were plotted for all criterion levels, and the area under the resulting ROC curve gave the probability of distinguishing the two stimuli based on spike count (Cohn et al., 1975).

\section{Results}

Responses of DSCF neurons are facilitated by the FM, and $\mathrm{CF}_{2}$ of the biosonar signal

DSCF neurons were sharply tuned to the echo $\mathrm{CF}_{2}$, as reported in previous studies (Suga and Jen, 1976; Suga, 1977; Suga and 
Manabe, 1982; Suga et al., 1987). In addition to the $\mathrm{CF}_{2}$ response, however, DSCF neurons were facilitated by the pulse $H_{1}$, and specifically by the $F_{1}$. By facilitation it is meant that the neuron's response to the paired stimuli is greater than the sum of the responses to individual stimuli. To obtain maximum facilitation to the $\mathrm{H}_{1}-\mathrm{H}_{2}$ or $\mathrm{FM}_{1}-\mathrm{CF}_{2}$ combinations, some echo delay was required (as will be fully described in a later section); the best echo delay for the neuron in Figure 2 was $26.0 \mathrm{msec}$. As can be seen, the neuron responded weakly to the best $\mathrm{H}_{1}$ alone (Fig. 2a) and modestly to the best $\mathrm{H}_{2}$ alone (Fig. 2b). When the $\mathrm{H}_{1}$ was paired with the $\mathrm{H}_{2}$ (Fig. $2 c$ ), the response was facilitated. When the $\mathrm{FM}_{1}$ was removed, the response declined to the level of the $\mathrm{H}_{2}$ only (Fig. $2 d$ ). When only the FM, and $\mathrm{CF}_{2}$ were presented, the facilitation was as strong as that to the complete harmonics (Fig. 2e). Thus, the essential components for facilitation of this neuron were the $\mathrm{FM}_{1}$ and $\mathrm{CF}_{2}$, as was true of all ( $n=142$ ) DSCF neurons examined in this study.

\section{Tuning to pure tones}

When a "best" pure tone within the frequency range of the FM was substituted for the $\mathrm{H}_{1}$ and presented together with the $\mathrm{CF}_{2}$, facilitation of DSCF neurons occurred without the necessity of introducing echo delay (Fig. 3). We called this pure tone the best "FM $\mathrm{F}_{1}$ frequency." For the neuron in Figure $3 A$, the best $\mathrm{FM}_{1}$ frequency for facilitation was $25.98 \mathrm{kHz}$ delivered at 72 dB SPL and the best $\mathrm{CF}_{2}$ was $62.70 \mathrm{kIIz}$ at $47 \mathrm{~dB}$ SPL. This neuron had a good response to the $\mathrm{CF}_{2}$ alone (120 spikes to 100 stimuli in a $100 \mathrm{msec}$ time window), as did most neurons tested, but was clearly facilitated when both stimuli were present (202 spikes). The best $\mathrm{CF}_{2}$ measured when the $\mathrm{CF}_{2}$ was presented alone typically had the same frequency as the $\mathrm{CF}_{2}$ presented as part of a facilitatory pair. The neuron in Figure $3 B$ shows a response similar to that in $3 A$, except that it responded well to both the best $\mathrm{FM}_{1}$ frequency alone and the best $\mathrm{CF}_{2}$ alone $(25.80$ $\mathrm{kHz}$ at $77 \mathrm{~dB}$ SPL and $61.60 \mathrm{kHz}$ at $12 \mathrm{~dB}$ SPL, respectively). Like the neuron in Figure $3 A$, however, facilitation occurred when both components were presented together. For the 60 neurons tested, the average best FM, frequency for facilitation was $26.34 \pm 0.824 \mathrm{kHz}$ at $71 \pm 5.5 \mathrm{~dB}$. This average best frequency is well below that of the lowest $\mathrm{CF}_{1}$ emitted by the bats (about $28 \mathrm{kHz}$ ), but is within the range of the $\mathrm{FM}_{1}$ (which sweeps from $28-31 \mathrm{kHz}$ to $22-25 \mathrm{kHz}$ ). The average best $\mathrm{CF}_{2}$ was $61.56 \pm 0.670 \mathrm{kHz}$ at $36 \pm 11.9 \mathrm{~dB}$, which is typical of the Doppler shift-compensated echo $\mathrm{CF}_{2}$. The average minimum threshold to the $\mathrm{FM}_{1}$ frequencies at the best frequency for facilitation was $52 \pm 5.3 \mathrm{~dB}$, and for the $\mathrm{CF}_{2} \mathrm{~s}$ was $16 \pm 11.7$ dB. The large best amplitude and minimum threshold differences between the components indicate that in nature the $\mathbf{H}_{1}$ response is to the loud outgoing pulse while the $\mathrm{CF}_{2}$ response is to the much fainter echoes.

A complete description of excitatory, inhibitory, and facilitative frequency tuning curves will be the subject of a later report, and so will be only highlighted here. In 15 neurons in which the best $F M_{1}$ frequency was fixed and the $\mathrm{CF}_{2}$ was varied in frequency, the $\mathrm{CF}_{2}$ tuning widths (to the $50 \%$ maximum response contour measured at the best $\mathrm{CF}_{2}$ amplitude for facilitation and with $0 \mathrm{msec}$ echo delay) averaged $11 \pm 7.4 \%$ broader than when the $F M_{1}$ frequency was not present. The minimum threshold to the $\mathrm{CF}_{2}$ was lowered by an average of $9.8 \pm 10.1$ $\mathrm{dB}$. Thus, facilitation by the best $\mathrm{FM}_{1}$ frequency can both broaden the frequency tuning and lower the threshold to the $\mathrm{CF}_{2}$, but by relatively small and variable amounts.

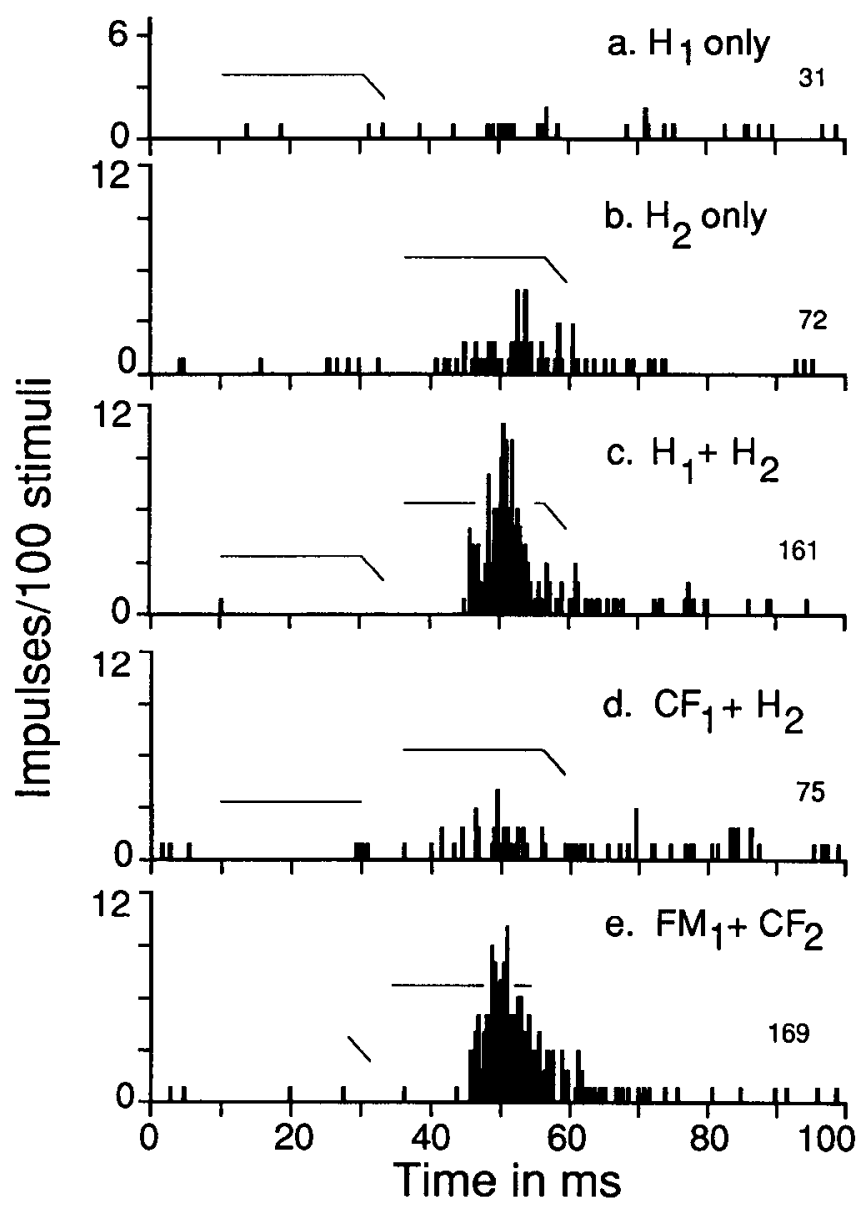

$\begin{aligned} & \text { Unit J-9-5-91-12 } \\ & \mathrm{H}_{1}: 29.10 \rightarrow 23.10 \mathrm{kHz} \\ & 72 \mathrm{~dB} \mathrm{SPL} \\ & \mathrm{H}_{2}: 61.20 \rightarrow 49.10 \mathrm{kHz} \\ & 17 \mathrm{~dB} \mathrm{SPL} \\ & \text { Echo delay }= 26 \mathrm{~ms}\end{aligned}$

Figure 2. Demonstration of the csscntial components for DSCF neuron facilitation. The response of this neuron was small to the $\mathrm{H}_{1}$ or $\mathrm{H}_{2}$ presented alone ( $a$ and $b$, respectively), but facilitation occurred to the $\mathbf{H}_{1}-\mathrm{H}_{2}$ pulse-echo pair $(c)$. When the $F M_{1}$ was eliminated $(d)$ the facilitation disappeared, but the facilitation to the $\mathrm{FM}_{1}-\mathrm{CF}_{2}$ pair $(e)$ was as strong as to the complete harmonics (compare $c$ and $e$ ). The pulse $\mathrm{FM}_{1}$ and echo $\mathrm{CF}_{2}$ are therefore the essential components for facilitation. The best frequencies and amplitudes for each component and the best echo delay for this neuron are indicated. Small numbers to the right of each histogram are the spike counts.

\section{Magnitude of the facilitation}

The magnitude of the facilitatory interactions between two stimulus components can be expressed as a facilitation ratio (FR), defined as the paired response (number of impulses) divided by the sum of the responses to each component alone, for stimuli at the best frequencies and amplitudes for facilitation and with spontaneous activity subtracted. For 60 facilitated DSCF area neurons tested with $\mathrm{FM}_{1}$ frequencies and $\mathrm{CF}_{2} \mathrm{~s}$, the $\mathrm{FRs}$ ranged from 1.2 to 5.7 , with a median of 1.7. For most ncurons, the response to the $F M_{1}$ frequency alone was weak or absent, but in $14(23 \%)$ the $\mathrm{FM}_{1}$ frequency alone response was as large or larger than the response to the $\mathrm{CF}_{2}$ alone. For an additional 55 neurons tested with $\mathrm{H}_{1}-\mathrm{H}_{2}$ pairs at the best delay, the FRs ranged 
Figure 3. Facilitation of DSCF neurons to the best $\mathrm{FM}_{1}$ frequency and $\mathrm{CF}_{2}$. $A$, In this neuron, the response to the best $\mathrm{FM}_{1}$ frequency alone $(a)$ was small, and the response to the best $\mathrm{CF}_{2}$ alone (b) was modest. When both were presented together $(c)$, facilitation occurred; for pairs of pure tone stimuli such as this echo delay was not required for facilitation. $B$, For this neuron, the response to the $\mathrm{FM}_{1}$ frequency alone (a) was nearly equal to that of the $\mathrm{CF}_{2}$ alone (b), but facilitation still occurred when both were presented together $(c)$. Small numbers to the right of each histogram are the spike counts.

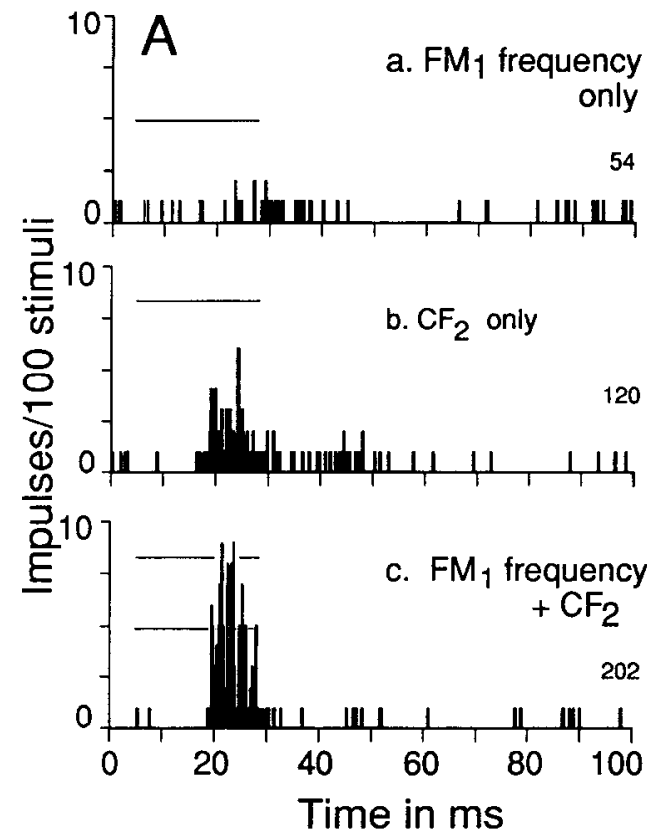

Unit J-9-5-91-5

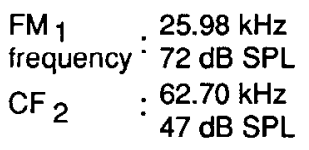

a
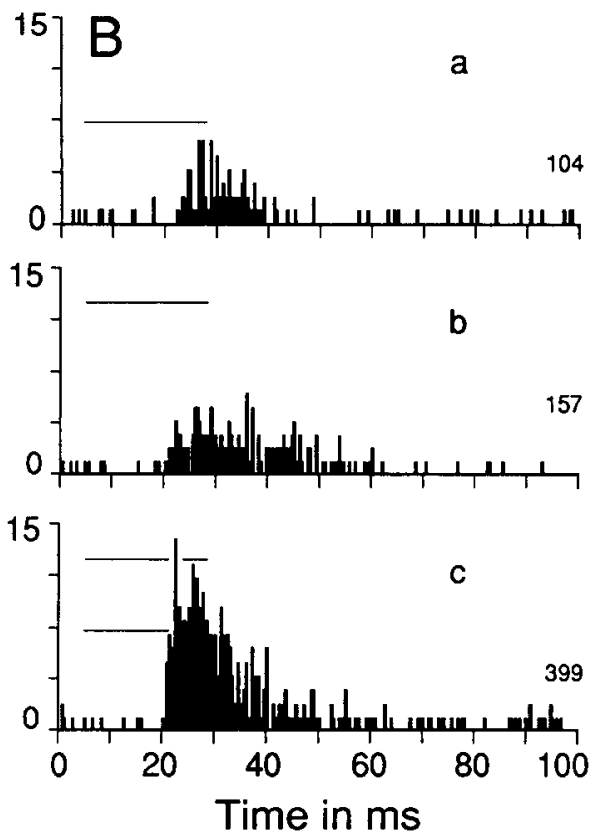

Unit J-9-5-91-7

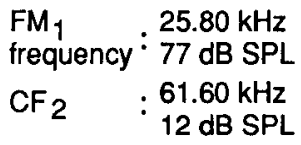

from 1.0 to 10.1 , with a median value of 2.4. Because the median and maximum FRs were higher to the best $\mathrm{H}_{1} \mathrm{~s}$ at the best delay than to the best $F M_{1}$ frequencies at 0 msec delay, the complete natural stimuli appear more facilitative than single frequencies, although both induce facilitation with a roughly twofold increase in the response magnitude.

With few exceptions, DSCF neurons showed clear facilitation. In a sample of 50 neurons from two hemispheres, $38(76 \%)$ were facilitated, that is, had FRs greater than 1.2 (an FR of 1.20 was used as the criterion level for facilitation to discount variability in the responses not related to facilitation). Of the 12 neurons with FRs less than 1.2, 8 responded reliably to the paired stimuli and only occasionally to the $\mathrm{CF}_{2}$ alone. However, the occasional $\mathrm{CF}_{2}$ alone response consisted of a burst of up to 10 impulses, whereas when both components were present the response typically had only one to five impulses, resulting in FRs less than 1.2. Thus, most DSCF neurons changed their firing pattern to the $\mathrm{CF}_{2}$ in the presence of an $\mathrm{FM}_{1}$ frequency.

\section{The facilitation of DSCF neurons is sensitive to echo delays}

As mentioned above, $\mathrm{H}_{1}-\mathrm{H}_{2}$ pairs evoke maximum facilitation at a particular echo delay. Since echo delay is used by bats to estimate target range (Simmons, 1973), we examined the effect of varying echo delay on the responses of 55 DSCF ncurons (scc Materials and Methods). For the neuron in Figure 4, no facilitation was evident for the longest echo delay tested of 47.5 msec (Fig. 4Aa-e). As the delay was shortened, facilitation first occurred at $27.5 \mathrm{msec}$ delay (Fig. $4 A \mathrm{~b}$ ) and reached a peak at $22.5 \mathrm{msec}$ echo delay (Fig. $4 A \mathrm{C}$ ). Further decreasing the echo delay caused the facilitation to decline (Fig. $4 A d$ ), but it rebounded at short delays, causing a second peak at $7.5 \mathrm{msec}$ echo delay (Fig. 4Ae). The response then declined again as echo delay was further shortened to $0 \mathrm{msec}$ (not shown). At the short delay peak, the $\mathrm{CF}_{2}$ arrived before the $\mathrm{FM}_{1}$, so that the $\mathrm{FM}_{1}$ appeared to facilitate an off-response to the $\mathrm{CF}_{2}$ or an on-response to the $\mathrm{FM}_{2}$ that was not otherwise apparent. Compared to the long delay response at $22.5 \mathrm{msec}$ echo delay, the short delay response was temporally more dispersed.

Neurons with a two-peaked response in which the short delay peak was at least $50 \%$ of the long-delay peak (as in Fig. $4 A$ ) were called type I $(45 \%, n=20)$. Those which had only a single major peak in their response were classed as type II $(55 \%, n=$ 30 ). In type II neurons, the major peak always occurred to echo delays longer than $15 \mathrm{msec}$. In five type I neurons, the short delay peak was higher than the long delay peak.

To estimate the population response of DSCF neurons to changing delays, we summed the response of the 55 neurons and normalized and plotted the result (Fig. $4 B e$ ). The maximal summed response occurred to an echo delay of $22.5 \mathrm{msec}$. The short delay peak of type I neurons was hardly apparent; however, the type I and very broadly tuned type II neurons served to maintain a wide (4.3-28.7 msec) delay response width measured at $50 \%$ of the maximal firing rate.

For individual type I and type II neurons, the 50\% delaytuning widths varied considerably. The neuron in Figure $4 B C$ had a $50 \%$ delay-tuning width of $17.5 \mathrm{msec}$, which was close to the population mean of $20.2 \pm 9.03 \mathrm{msec}$ for the 55 neurons. The neurons in Figure $4 B, c$ and $d$, are near the extremes in terms of delay-tuning widths, at $7.6 \mathrm{msec}$ and $39.9 \mathrm{msec}$, respectively. In Figure $4 C$ the distribution of $50 \%$ delay-tuning widths for the 55 neurons is plotted as a function of best delay. The wide range of delay widths encountered is evident. This figure also indicates that there was no correlation between best delays and $50 \%$ delay-tuning width. Such a correlation might 
A

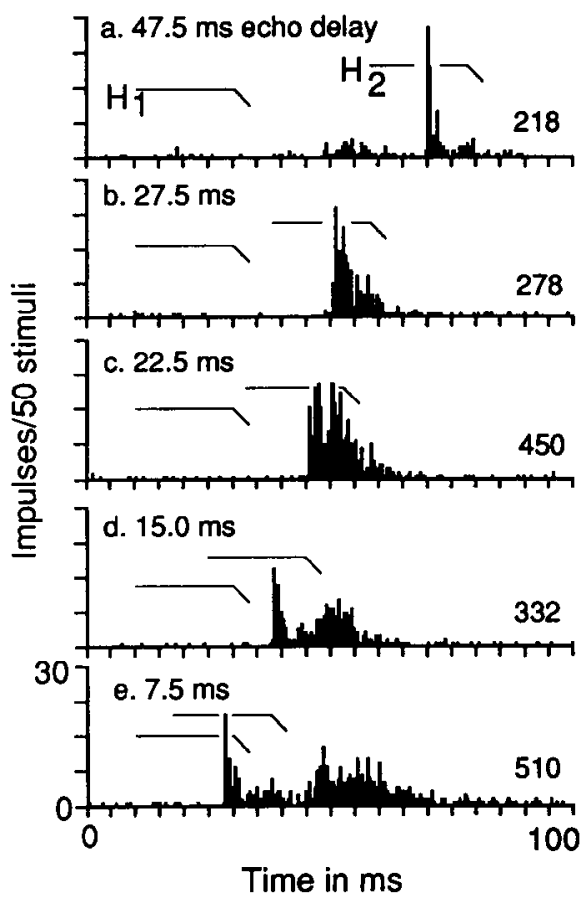

B

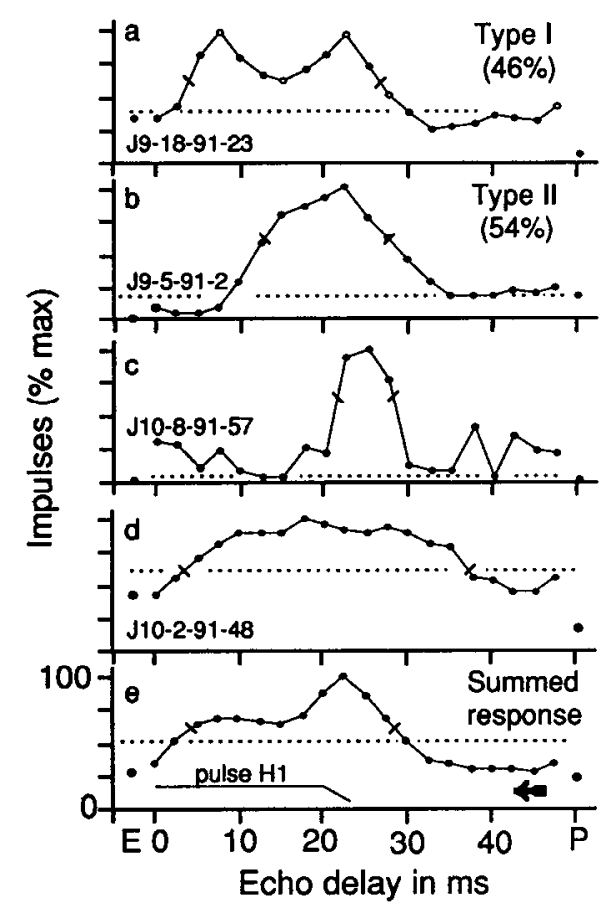

Figure 4. Responses of DSCF neurons to $\mathrm{H}_{1}-\mathrm{H}_{2}$ pairs of varying echo delay. $A$, PSTHs for pulse-echo pairs with different delays. For this neuron (J9-518-23), the pulse and echo responses are distinct at the longest delay tested $(47.5 \mathrm{msec})$. As the delay shortens and the responses merge, facilitation occurs, reaching a maximum at an echo delay of $22.5 \mathrm{msec}$. At a delay of 15.0 msec, the facilitation is less and the responses to each component are again separate but now the $\mathrm{H}_{2}$ response precedes the $H_{1}$ response. As the delay was shortened to $7.5 \mathrm{msec}$, the facilitation increased again, with the increased spikes likely due to a facilitation of a $\mathrm{CF}_{2}$ offset response not otherwise apparent. Small numbers to the right of each histogram are the total number of spikes at that delay. $B$, Differential tuning to changing echo delay among DSCF neurons. In $a$, the open circles represent the delays corresponding to the histograms in $A$. Neurons with this doublepeaked delay-dependent response were called type I, and neurons without the short-delay peak were called type II neurons $(b)$. Both type I and type II neurons had variable delay-tuning widths, examples of the extremes observed are shown in $c$ and $d$. In $e$, the summed response of the population is given. In each curve, the dotted lines indicate the sum of the pulse and echo alone responses, and the slashes through the curves indicate points of $50 \%$ maximum response. The arrow in $c$ indicates the direction that delay was changed in each stimulus train. All stimuli were delivered at the best frequencies and amplitudes for facilitation. $C$, The distribution of $50 \%$ delay response widths versus best delay for the population. The width of delay tuning was highly variable and did not correlate with echo delay. be expected because of Weber's law, which says that the justnoticeable difference between stimuli should scale with the magnitude of the stimuli, and because in the FM-FM and dorsal fringe (DF) areas the width of delay tuning is in fact a function of the best delay, conforming to Webcr's law (Suga and Horikawa, 1986). This result represents an important distinction between DSCF neurons and other delay-tuned neurons, because it indicates that although DSCF neurons are active in responses to echoes from targets at particular ranges, range is not the information-bearing parameter extracted by the neurons.

\section{$R O C$ analysis of the responses to changing echo delays}

Since the facilitation occurs to particular echo delays, that is, to targets within particular ranges, targets within these ranges should be detectable by means of the increase in spike count relative to the weaker responses to closer or more distant targets. To quantify the delays at which increased impulse counts due to facilitation signal the presence of a target, we constructed ROC curves from responses at each echo delay in comparison to the longest delay tested $(47.5 \mathrm{msec})$. An example of ROC curves obtained for two delays in one neuron are shown in Figure $5 A$. The points on the curve represent the probability of "hits" versus "false alarms" for criterion values of zero spikes to the maximum number obtained in response to either the long (47.5 $\mathrm{msec}$ ) or short ( $<47.5 \mathrm{msec}$ ) delay stimulus (sce Matcrials and Methods). The area under each curve represents the probability of correct discrimination $\mathrm{p}(\mathrm{CD})$ that the short delay stimulus was presented. For the $35.0 \mathrm{msec}$ stimulus, the $p(C D)$ was essentially chance at 0.55 , and for the $22.5 \mathrm{msec}$ stimulus the $p(C D)$ was near maximum for this neuron at 0.88 . The complete delay-discrimination curve for the neuron is shown in Figure $5 B$, with the points derived from the ROC curves in Figure $5 A$ indicated with open circles. From curves like those shown in Figure $5 B$, we measured the longest discriminable delay (LDD), the most discriminable delay (MDD), and the shortest discriminable delay (SDD), using the $75 \%$ correct discrimination level as the basis for defining the LDD and SDD, and the point of maximum discrimination as the MDD.

The distributions of LDDs, MDDs, and SDDs for the 55 neurons tested are shown in Figure $5 C$, and statistics for each 

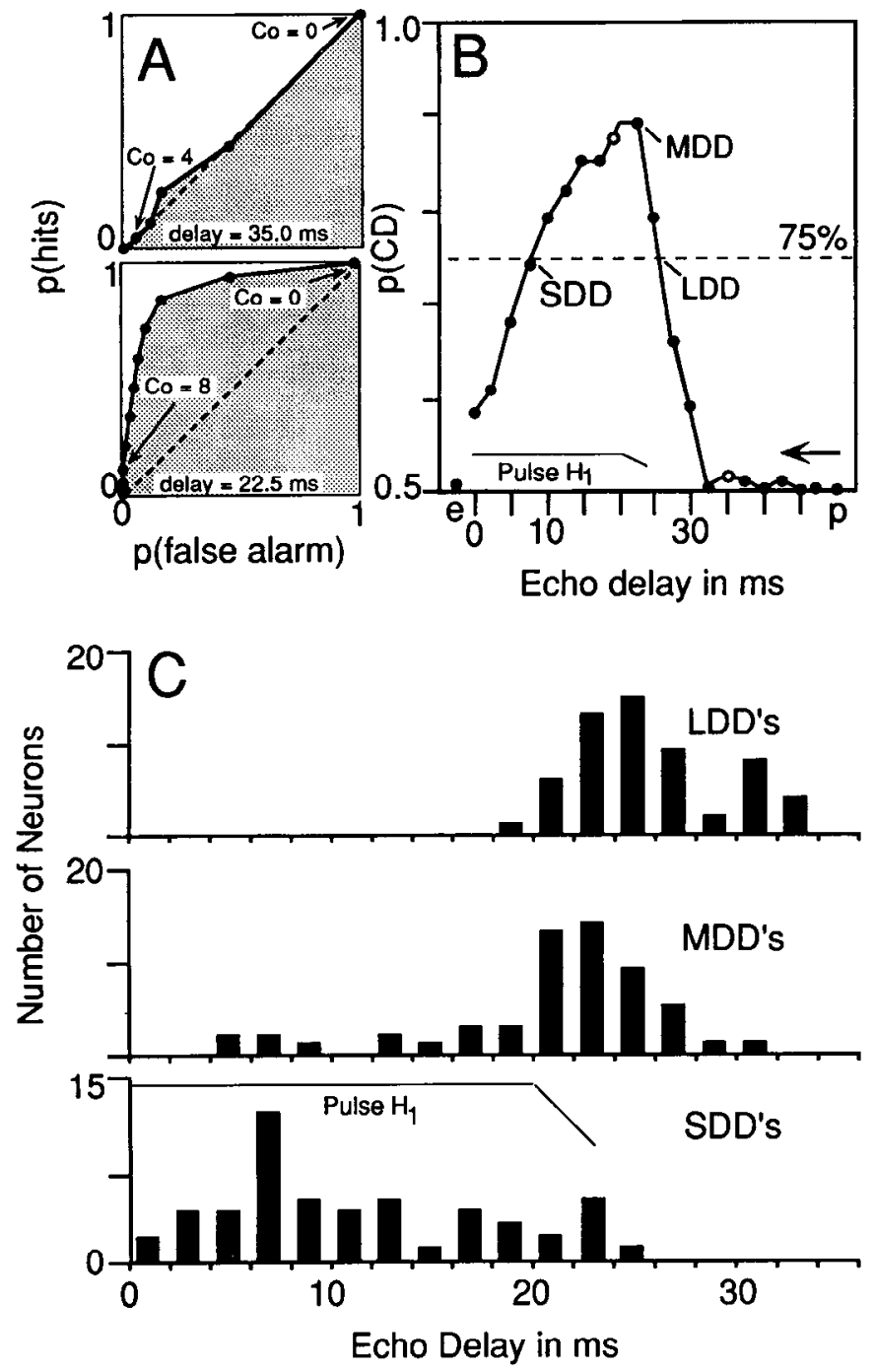

Figure 5. Delay discriminability determined by ROC analysis. $A$, Examples of ROC curves for stimuli with two different echo delays. The area under the curves (shaded) provides the probability that an ideal observer of this neuron's (J9-5-91-31) response could correctly discriminate that the echo delay presented was shorter than the longest tested $(47.5 \mathrm{msec})$. The $35.0 \mathrm{msec}$ delay stimulus could not be discriminated $[p(C D)=0.55$ or only slightly better than chance], while the $22.5 \mathrm{msec}$ delay stimulus could be correctly discriminated approximately $90 \%$ of the time $[p(C D)=0.88]$. Dashed line indicates the chance $[p(C D)=$ $0.5]$ level. $C o$, criterion level (i.e., a spike number from 0 to the maximum observed); $p$ (hits), probability that the short delay stimulus was presented and the criterion level was equaled or exceeded; $p$ (false alarms) probability that the $47.5 \mathrm{msec}$ echo delay stimulus was presented and the criterion level was equaled or exceeded. $B$, The complete delay discrimination curve. Points derived from the ROC curves in $A$ are shown as open circles. The $75 \%$ correct discrimination line, used to determine the LDD, MDD, and SDD (see text), is shown. The direction of the changing delay in the stimulus trains is shown by the arrow. $C$, The distributions of LDDs, MDDs, and SDDs for the 55 neurons tested.

are given in Table 1. The LDDs of the neurons occurred from about 19 to $33 \mathrm{msec}$ echo delay, and the MDDs from 5 to 30 msec delay. MDDs less than about $16 \mathrm{msec}$ occurred rarely $(14.5 \%, N=8)$ and only in type I neurons where the short delay peak was higher than the long delay peak or in very broadly tuned type II neurons. The SDDs were much more variable than the LDDs. In Table 1 , the target ranges corresponding to the means and extremes for the LDDs, MDDs, and SDDs are indicated. It can be seen that the maximum target range that would
Table 1. Echo delays and target ranges associated with the delaydependent responses of DSCF neurons

\begin{tabular}{lll} 
& $\begin{array}{l}\text { Echo delay } \\
(\mathrm{msec})\end{array}$ & $\begin{array}{l}\text { Target range } \\
(\mathrm{m})\end{array}$ \\
\hline LDD & $25.6 \pm 3.26(19.4-32.8)$ & $4.4 \pm 0.56(3.3-5.6)$ \\
MDD & $20.9 \pm 5.55(5.0-30.0)$ & $3.6 \pm 0.95(0.9-5.2)$ \\
SDD & $11.5 \pm 6.51(1.4-24.5)$ & $2.0 \pm 1.12(0.2-4.2)$
\end{tabular}

Values are mean \pm SD for the 55 neurons tested; those in parentheses are the extremes observed. Target ranges were calculated using $344 \mathrm{~m} / \mathrm{sec}$ as the speed of sound in air at $25^{\circ} \mathrm{C}$. LDD, Longest discriminable delay; MDD, most discriminable delay; SDD, shortest discriminable delay.

cause a detectable increase in the response of DSCF neurons as compared to more distant targets was about $5.5 \mathrm{~m}$, and most neurons would be facilitated by echoes from targets closer than $4.3 \mathrm{~m}$. The maximum point of detectability for the population occurred to targets about $3.6 \mathrm{~m}$ distant.

\section{Response latencies}

Because the latencies to the different facilitative components have proven useful for understanding mechanisms of delay tuning in FM-FM neurons (Olsen and Suga, 1991a), latencies of DSCF neurons were measured to the best $\mathrm{H}_{1}$ alone, the best $\mathrm{H}_{2}$ alone, and the best $\mathrm{H}_{1}-\mathrm{H}_{2}$ pair at best delay. The $\mathrm{H}_{1}$-alone and the $\mathrm{H}_{1}-\mathrm{H}_{2}$ latencies were measured from the beginning of the pulse $\mathrm{FM}_{1}$; the best $\mathrm{H}_{2}$-alone latency was measured from the beginning of the $\mathrm{CF}_{2}$. On average, latencies to the best $\mathrm{H}_{1}$ alone were $7.8 \mathrm{msec}$ longer than to the best $\mathbf{H}_{2}$ (Table 2). However, the echo delays that caused the latencies of pulse and echo to coincide was rarely the best delay (or MDD); rather, the latency at the MDD occurred $3.2 \mathrm{msec}$ prior to the pulse latency on average. For the neurons in Figure $6 A$, it can be seen that at the MDD (22.5 msec), the facilitation occurred prior to the onset of the $\mathrm{H}_{1}$-alone response. The delay that would cause the excitatory responses to the pulse and echo to coincide $(27.5 \mathrm{msec})$ was not the best delay. Similarly, for the neuron in Figure $6 B$ it can be seen that facilitation to the best $F M_{1}$ frequencies and $\mathrm{CF}_{2} \mathrm{~s}$ occurred prior to the pulse only response.

\section{The effect of changing CF duration on the delay tuning of DSCF neurons}

The delay-response and ROC curves presented above were obtained to stimuli of constant duration $(20 \mathrm{msec} C F$ and $3 \mathrm{msec}$ FM). Signals of this duration are typical of those emitted during the search phase of echolocation (Novick and Vaisnys, 1964;

Table 2. Response latencies

Facilitated latency at best delay (measured

\begin{tabular}{llll} 
& $\begin{array}{l}\mathrm{FM}_{1} \text { alone } \\
\text { latency } \\
(\mathrm{msec})\end{array}$ & $\begin{array}{l}\mathrm{CF}_{2} \text {-alone } \\
\text { latency } \\
(\mathrm{msec})\end{array}$ & $\begin{array}{l}\begin{array}{l}\text { (measured } \\
\text { from the }\end{array} \\
\left.\mathrm{FM}_{1}\right) \\
(\mathrm{msec})\end{array}$ \\
\hline Mean & 18.1 & 10.3 & 14.9 \\
Rangc & $11.7-23.5$ & $5.7-16.5$ & $8.1-24.5$ \\
$\mathrm{SD} / \mathrm{SE}$ & 2.57 & 3.01 & 3.31 \\
$N$ & 31 & 48 & 55
\end{tabular}

$\overline{\text { Data were obtained from } 31 \text { neurons with pulse-alone responses vigorous enough }}$ for the latency to be measured. An acoustic delay of 2.3 msec has been subtracted. 

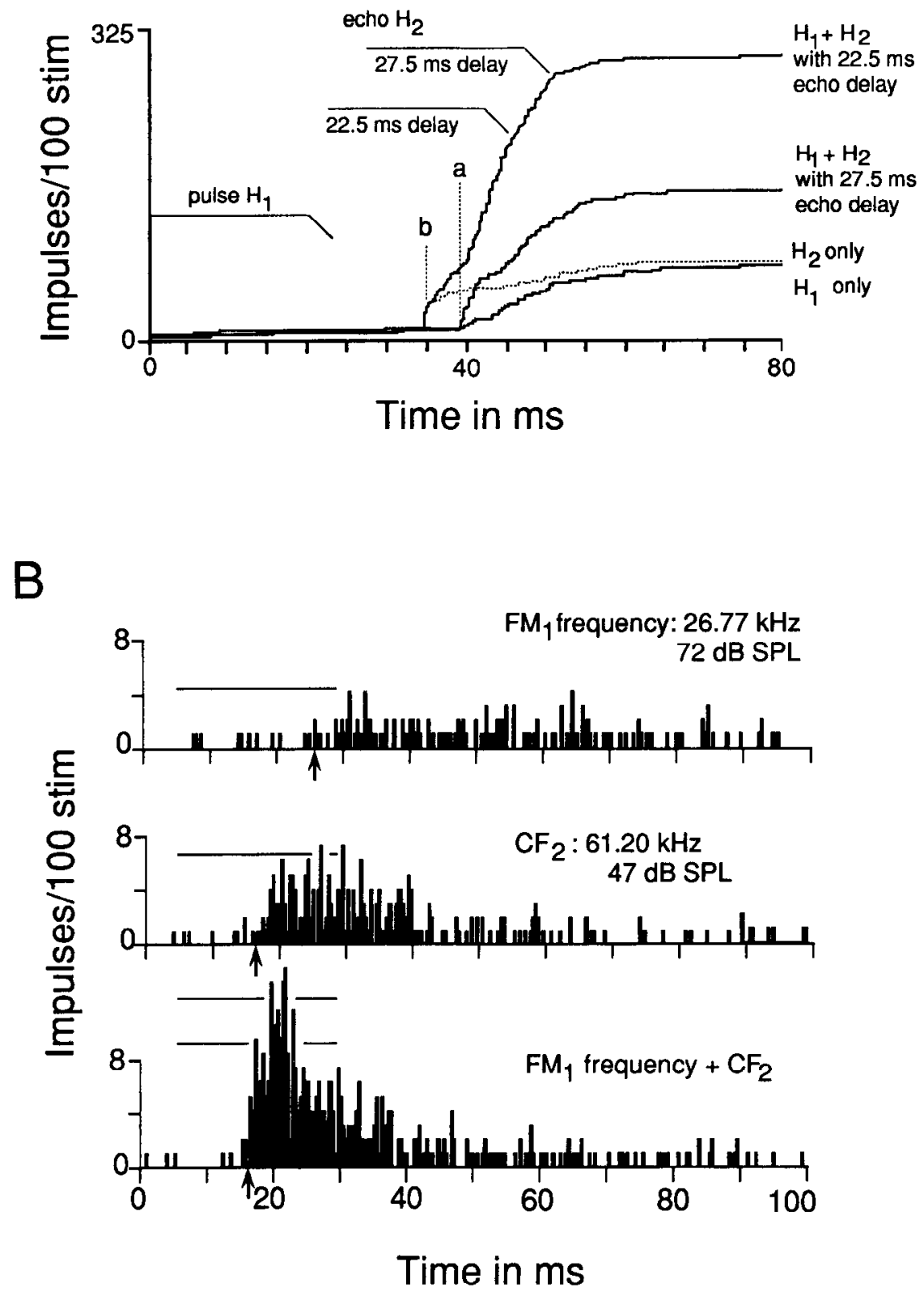

Figure 6. A, Cumulative histograms of the responses of a DSCF neuron (J95-91-33) to the $\mathrm{H}_{1}$-alone, $\mathrm{H}_{2}$-alone, and two $\mathrm{H}_{1}-\mathrm{H}_{2}$ pairs with different delays $(22.5$ and $27.5 \mathrm{msec})$. Best delay (22.5 msec) occurred when the $\mathrm{H}_{2}$ response preceded the $H_{1}$ response by about 5 msec (point $b$ ), rather than at the delay ( $27.5 \mathrm{msec}$ ) where the $\mathrm{H}_{1}$ and $\mathrm{H}_{2}$ responses coincided (point a). The $\mathrm{H}_{2-}$ alone response (broken line) was shifted along the $\mathrm{x}$-axis and superimposed on the response at best delay to show that facilitation occurred prior to the onset of the pulse-alone response. $B, \mathrm{Re}$ sponses to $\mathrm{H}_{1}$ tones and $\mathrm{CF}_{2}$ s. In this neuron (J9-5-91-12), the pulse latency was $17.2 \mathrm{msec}$ and the echo latency was $11.6 \mathrm{msec}$. Facilitation began earlier than the observed response to the pulse alone, as indicated by arrows.

Henson et al., 1987). Once an insect is detected, however, the duration of the CF initially lengthens to $25-30 \mathrm{msec}$ and then progressively shortens to less than $10 \mathrm{msec}$ as the target is approached (Novick and Vaisnys, 1964; Henson, 1987). Because the $\mathrm{FM}_{1}$ occurs after the $\mathrm{CF}_{1}$ while the echo delay is measured from the pulse onset, shifts in echo delay tuning are expected with changing CF duration. Such shifts are illustrated for two neurons in Figure 7, where the effects of changing pulse duration on the LDDs and SDDs are plotted. It can be seen that the LDDs "tracked" changes in pulse duration, while the SDDs remained constant. Similar shifts in LDDs with pulse duration were found in all neurons examined $(n=5)$.

\section{Discussion}

We have demonstrated that DSCF neurons show facilitative responses to $\mathrm{FM}_{1}-\mathrm{CF}_{2}$ combination in biosonar signals, and that the facilitation is echo delay dependent. In the following discussion, we focus on echolocation tasks to which DSCF neurons are likely to contribute, and consider implications of the results for the organization of auditory and sensory cortex in other species.

\section{Behavioral significance of combination sensitivity and delay tuning of DSCF neurons}

Detection of background objects. Doppler shift compensation is thought to be a strategy by which the relative velocity of flying insects and modulations from insect wingbeats produce echoes distinguishable from those produced by nonmoving background objects (Schnitzler, 1970a,b; Simmons, 1973; Johnson, 1974; Schnitzler et al., 1983). The horseshoe bat, Rhinolophus ferrumequinum, is an old-world species not closely related to mustached bats but that uses similar CF-FM biosonar signals and 


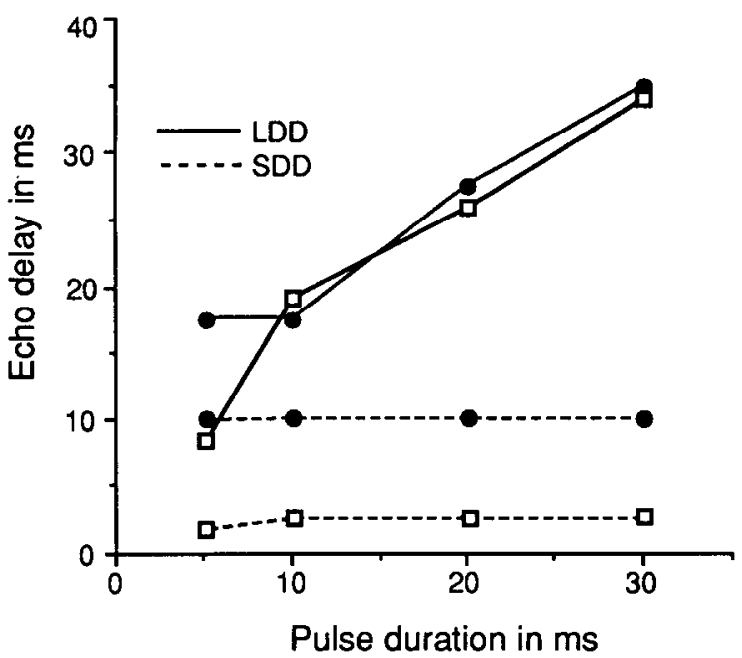

Figure 7. The effect of changing CF duration on the delay-dependent response of two DSCF neurons (closed and open circles, respectively). The LDDs but not the SDDs increased with pulse duration.

shows Doppler shift compensation. Horseshoe bats Doppler shift compensate only to echoes from background objects and not insect targets (Trappe and Schnitzler, 1982). In mustached bats, most DSCF neurons are sensitive to the reference frequency (Suga et al., 1987) and lesion experiments have shown that an intact DSCF area is necessary for complete Doppler shift compensation (Gaioni et al., 1988). Thus, many DSCF neurons can be expected to respond to echoes from background objects. Our experiments suggest that most DSCF neurons will be facilitated by echoes from objects within a range of about 1.9-4.3 $\mathrm{m}$, and the greatest distance at which a target would be detectable by the facilitation is about $5.5 \mathrm{~m}$. Because of the considerable spread of best delays found among DSCF neurons and the typically broad delay tuning, the neurons can respond to targets located over a wide range of distances. Since mustached bats hunt in the acoustically cluttered, dense foliage of the new-world neotropics (Bateman and Vaughn, 1974), DSCF neuron facilitation may be important for maintaining an appropriate distance from background objects for optimal foraging.

Detection of insect targets by DSCF neurons. Both mustached bats and horseshoe bats attack only flying insects, that is, those that are beating their wings (Goldman and Henson, 1978; Schnitzler and Henson, 1980). Insect wingbeats produce modulations of echo amplitude and frequency, and these modulations cause the echoes from the wings to sweep through the response areas of DSCF neurons in a periodic fashion. Approximately $50 \%$ of the DSCF neurons show periodic responses to sinusoidally frequency modulated (SFM) stimuli that mimic echoes from beating wings (Suga et al., 1983a). Thus, DSCF neurons presumably respond to echoes from flying insects as well as background targets. The delay tuning of DSCF neurons observed in this study coupled with previous behavioral observations suggest a role for DSCF neurons in detecting insect targets. That is, mustached bats first pursue flying insects when they come within a range of 3-4 m (Novick and Vaisnys, 1964; Henson et al., 1987). For search phase pulses of $20-25 \mathrm{msec}$ this distance closely corresponds to LDDs and MDDs typically obtained from DSCF neurons (Fig. $5 \mathrm{C}$ ). Thus, the delay tuning of DSCF neurons correlates with the range at which the bats appear to detect insect targets. Possibly, DSCF neuron facili- tation is instrumental in initiating the transition from the search to the approach phase of echolocation.

Characterization of insect targets by DSCF neurons. Several response properties of DSCF neurons indicate they may have a role in target characterization. These include periodic responses to SFM stimuli with frequency modulation depths in behaviorally relevant ranges (Suga et al., 1983a), and regular mapping of echo amplitude, which is a measure of target subtended angle (Suga, 1977; Manabe et al., 1982). During the approach phase, the bat initially increases the pulse duration (to $25-30 \mathrm{msec}$ ) and then decreases it until the pulses are about $10 \mathrm{msec}$ long at the end of the phase (Novick and Vaisnys, 1964; Henson et al., 1987). The reason for the initial pulse lengthening may be to increase the number of wingbeat cycles in the echo, presumably to aid in characterization (Schnitzler and Flieger, 1983). Since the bat moves closer to the insect while this lengthening occurs, it is significant that most DSCF neurons are widely tuned to delay and remain facilitated even in the presence of considerable pulse-echo overlap (Fig. 7). Later in the approach phase, the best delay of DSCF neurons shifts with the decreasing $\mathrm{CF}$ duration, which should serve to maintain the neurons near their maximal degree of facilitation during most of the phase. Thus, DSCF neurons would be facilitated during much of the approach phase, when target characterization is presumably occurring.

\section{Possible mechanisms of facilitation and delay tuning for DSCF neurons}

The facilitation of DSCF neurons begins prior to any apparent pulse response (Figs. 3, 6; Table 2), so the pulse $\mathrm{FM}_{1}$ appears to produce an EPSP that does not reach spike threshold for several milliseconds. No correlation between pulse and echo latency and the best delay, such as described for FM-FM neurons (Olsen and Suga, 1991a), was observed in DSCF neurons. The long-latency responses to the pulse, however, suggest that pulse channel delay lines are important for DSCF neurons, as for FMFM neurons (Olsen and Suga, 1991a).

Anatomically, there are no intracortical connections that could account for the $\mathrm{FM}_{1}$ and $\mathrm{CF}_{2}$ frequencies becoming combined in the DSCF area (D. C. Fitzpatrick and N. Suga, unpublished observations). By contrast, fibers from the $\mathrm{H}_{1}$ representation in the inferior colliculus are widespread in the MGB, including the ventral division (Wenstrup and Winer, 1987). FM-FM and CF/ CF neurons are found in the MGB and cortex (Olsen and Suga, $1991 \mathrm{a}, \mathrm{b})$ but not in the inferior colliculus (O'Neill, 1985), suggesting that these types of combination-sensitive neurons are first created in the MGB. In the MGB, some CF/CF neurons show facilitated responses to frequencies typical of the $\mathrm{FM}_{1}$ rather than the $\mathrm{CF}_{1}$ (Olsen and Suga, 1991b). Thus, rather than the cortex, it is probably the MGB where $\mathrm{FM}_{1}$ and $\mathrm{CF}_{2}$ signals first converge to create $\mathrm{FM}_{1}-\mathrm{CF}_{2}$ combination-sensitive neurons.

\section{Comparison of DSCF neurons with other combination-sensitive neurons in the mustached bat's auditory cortex}

The $\mathrm{FM}_{1}-\mathrm{CF}_{2}$ combination sensitivity of DSCF neurons represents the fourth class of combination-sensitive neurons described in this cortex. FM-FM neurons, found in the FM-FM, DF, and ventral fringe (VF) areas (O'Neill and Suga, 1982; Suga and Horikawa, 1988; Edamatsu et al., 1989) are facilitated by $\mathrm{FM}_{1}-\mathrm{FM}_{n}$ combinations $(N=2,3$, or 4$)$ and are more sharply tuned to echo delays than are DSCF neurons. $\mathrm{CF} / \mathrm{CF}$ neurons 
are facilitated by the $\mathrm{CF}_{1} / \mathrm{CF}_{N}(n=2$ or 3$)$ combinations and often respond maximally to synthesized echoes with $0 \mathrm{msec}$ delay and considerable pulse-echo overlap, which is why the abbreviations for the essential components are separated by a slash rather than a dash (Suga et al., 1983a). $\mathrm{H}_{1}-\mathrm{H}_{2}$ neurons that respond to various combinations of $\mathrm{H}_{1}$ and $\mathrm{H}_{2}$ components have been localized to a small area just ventral and anterior to the DSCF area (Tsuzuki and Suga, 1988). However, the combination-sensitive and delay-tuned responses of $\mathrm{FM}_{1}-\mathrm{CF}_{2}$ neurons described in this study are similar to those reported for $\mathrm{H}_{1}-\mathrm{H}_{2}$ neurons, so whether the $\mathrm{H}_{1}-\mathrm{H}_{2}$ area is in fact a discrete area, separate from the DSCF area, is questionable.

The present results suggest that functional areas in the auditory cortex are sequentially activated during insect pursuit. DSCF neurons are most active to echo delays between 11 and $26 \mathrm{msec}$, that is, to targets about $2-4 \mathrm{~m}$ distant. For echo delays less than $10 \mathrm{mscc}$, about $50 \%$ of DSCF ncurons no longer respond, and by $5 \mathrm{msec}$ delay only about $10 \%$ respond. By contrast, $95 \%$ of neurons in the FM-FM area have best delays of $10 \mathrm{msec}$ or less (Suga and O'Neill, 1979; O'Neill and Suga, 1982), as do all FM-FM neurons in the DF and VF areas (Suga and Horikawa, 1986; Edamatsu et al., 1989). Likewise, CF/CF neurons are in general broadly tuned to echo delay, but the responses typically decline for delays longer than about $10 \mathrm{msec}$ (Suga et al., 1983b; Olsen and Suga, 1991b). Thus, the FM,$\mathrm{CF}_{2}$ neurons in the DSCF area would be most active during the early and middle stages of echolocation, while neurons in the FM-FM and CF/CF areas would become active as insects or other objects of interest were neared.

A feature of primary importance in the FM-FM, DF, and CF/ CF areas is the regular mapping of an important information bearing parameter, that is, target range or velocity. At present, our data do not suggest a mapping of echo delay in the DSCF area, but the question has not been systematically addressed. Most DSCF neurons are facilitated by a broad range of echo delays and "track" changes in pulse duration so that they cannot encode range unambiguously, suggesting that they are not important for ranging per se and that a delay map in the DSCF area would not be useful. Echo frequency and amplitude are systematically represented in the DSCF area (Suga and Jen, 1976; Suga, 1977; Suga and Manabe, 1982; Suga et al., 1987).

\section{Significance for the organization of the auditory cortex in} other species

In the FM bat Myotis lucifigus, as many as $70-80 \%$ of the total neurons in the auditory cortex are delay sensitive (Sullivan, 1982; Wong et al., in press). In the mustached bat, delay-sensitive neurons (found in the FM-FM, DF, DSCF CF/CF, VF, and VA areas) occupy about $62 \%$ of the auditory cortex (Fitzpatrick and Suga, 1990). Neurons in the DSCF area account for about $26 \%$ of the delay-tuned neurons. In Myotis, about $30 \%$ of delay-tuned cortical neurons are "tracking" neurons whose peak of delay sensitivity changes during the insect pursuit sequence (Tanaka et al., 1992). By analogy with DSCF area neurons it may be that the delay sensitivity of Myotis "tracking" neurons is indicative of roles in target detection or characterization rather than ranging.

Unlike the combination-sensitive neurons previously described in the CF/CF, FM-FM, DF, VF, and $\mathrm{H}_{1}-\mathrm{H}_{2}$ areas, the DSCF area is clearly part of AI, as shown by its location within the main tonotopic array of the auditory cortex (Suga and Jen, 1976) and by its connections with the ventral division of the
MGB (Olsen, 1986). Occasional selective responses to speciesspecific sounds (i.e., responses to some sounds but not others) have been reported in AI of non-bat species, including squirrel monkey (Wollberg and Newman, 1972; Newman and Wollberg, 1973a,b; Winter and Funkenstein, 1973), and humans (Creutzfeldt et al., 1989), but no studies have yet shown combination sensitivity of cortical neurons in a non-bat species to particular information-bearing parameters in behaviorally significant sounds. Previous results from the mustached bat, however, suggest that neurons in auditory cortex of other species may be specialized to represent information-bearing parameters contained within complex sounds, and the present results indicate that such neurons can even occur in AI.

Similar to the DSCF area, the primate visual and somatosensory cortices contain expanded representations of densely innervated regions of the sensory surface. Such expanded representations are generally regarded as a passive conscquence of the the dense peripheral innervation. Thus, in primates there are as yet no suggestions of processing mechanisms unique to the expanded portions of sensory cortex. This is surprising, since many visual and textural details of objects cannot be resolved until the objects are foveated or manipulated by the fingers, and much neural machinery is devoted to bringing these sensory surfaces to bear on objects of interest. In the DSCF area, great sensitivity and high resolution appear essential for roles in the detection and characterization of targets, but additional specializations such as combination sensitivity and delay tuning also occur. Preliminary experiments indicate that such specializations do not occur in posterior $\mathrm{AI}$ (Fig. $1 \mathrm{~A}$ ), where frequencies below $61 \mathrm{kHz}$ are represented. We might expect to find neural response specializations in addition to high resolution within expanded representations in visual and somatosensory cortex of other species.

\section{References}

Bateman GC, Vaughn TA (1974) Nightly activities of mormoopid bats. J Mammol 55:45-65.

Brugge J (1985) The auditory cortex. In: Cerebral cortex, Vol 4 (Peters A, Jones EG, eds), pp 309-334. New York: Plenum.

Cohn TE, Green DG, Tanner WP Jr (1975) Receiver operating characteristic analysis. Application of the study of quantum fuctuation effects in optic nerve of Rana pipiens. J Gen Physiol 66:583-616.

Covey E, Vater M, Casseday JH (1991) Binaural properties of single units in the superior olivary complex of the mustached bat. J Neurophysiol 66:1080-1094.

Creutzfeldt O, Ojemann G, Lettich E (1989) Neuronal activity in the human temporal lobe. I. Responses to speech. Exp Brain Res 77:451475.

Edamatsu H, Kawasaki M, Suga N (1989) Distribution of combination-sensitive neurons in the ventral fringe area of the auditory cortex of the mustached bat. J Neurophysiol 61:202-207.

Fitzpatrick DC, Suga N (1990) The size and number of cortical columns in the mustached bat's auditory cortex. Soc Neurosci Abstr 16: 795.

Gaioni SJ, Suga N, Riquimaroux H (1988) Effects of bilateral ablation of the auditory cortex and/or cingulate cortex on the biosonar behavior of the mustached bat. Soc Neurosci Abstr 14:1100.

Goldman LJ, Henson OW Jr (1977) Prey recognition and selection by the constant frequency bat, Pteronotus $p$. parnellii. Behav Ecol Sociobiol 2:411-419.

Henson OW Jr, Bishop A, Keating A, Kobler J, Henson M, Wilson B, Hansen R (1987) Biosonar imaging of insects by Pteronotus p. parnellii, the mustached bat. Natl Geogr Res 3:82-101.

Kossl M, Vater M (1985) The cochlear frequency map of the mustache bat, Pteronotus parnelli. J Comp Physiol 157:687-697.

Manabe J, Suga N, Ostwald J (1978) Aural representation in the Doppler-shifted-CF processing area of the auditory cortex of the mustache bat. Science 200:339-342. 
Newman JD, Wollberg Z (1973a) Responses of single neurons in the auditory cortex to variants of a single cell type. Exp Neurol 40:821824.

Newman JD, Wollberg Z (1973b) Multiple coding of species-specific vocalizations in the auditory cortex of squirrel monkeys. Brain Res 54:287-304.

Novick A, Vaisnys JR (1964) Echolocation of flying insects by the bat Chilonycteris parnellii. Biol Bull 127:478-488.

Olsen JF (1986) Processing of biosonar information by the medial geniculate body of the mustached bat. PhD thesis, Washington University, St. Louis.

Olsen JF, Suga N (1991a) Combination-sensitive neurons in the medial geniculate body of the mustached bat: encoding of relative velocity information. J Neurophysiol 65:1254-1274.

Olsen JF, Suga N (1991b) Combination-sensitive neurons in the medial geniculate body of the mustached bat: encoding of target range information. J Neurophysiol 65:1275-1296.

O'Neill WE (1985) Responses to pure tones and linear FM components of the CF-FM biosonar signal by single units in the inferior colliculus of the mustached bat. J Comp Physiol A 157:797-815.

O'Neill WE, Suga N (1982) Encoding of target-range information and its representation in the auditory cortex of the mustached bat. J Neurosci 2:17-31.

Pollack GD, Bodenhamer RG (1981) Specialized characteristics of single units in inferior colliculus of the mustache bat: frequency representation, tuning, and discharge patterns. J Neurophysiol 46:605620.

Pollack GD, Henson OW Jr, Novick A (1972) Cochlear microphonic audiograms in the "pure tone" bat Chilonecteris parnellii parnellii. Science 176:66-68.

Schnitzler H-U (1970a) Comparison of the echolocation behavior in Rhinolophus ferrum-equinum and Chilonycteris rubiginosa. Bijdr Dierk 40:77-80.

Schnitzler H-U (1970b) Echoortung bei der Fledermaus, Chilonycteris rubiginosa. Z Vgl Physiol 68:25-38.

Schnitzler H-U, Flieger E (1983) Detection of oscillating target movements by echolocation in the greater horseshoe bat. J Comp Physiol A 153:385-391.

Schnitzler H-U, Henson OW Jr (1980) Performance of airborne animal sonar systems. I. Microchiroptera. In: Animal sonar systems (Busnel R-G, Fish JF, eds), pp 109-181. New York: Plenum.

Schnitzler H-U, Menne D, Kober R, Heblich K (1983) The acoustical image of fluttering insects in echolocating bats. In: Neuroethology and behavioral physiology (Huber F, Markl H, eds), pp 235-250. Berlin: Springer.

Simmons JA (1973) The resolution of target range by echolocating bat. J Acoust Soc Am 54:157-173.

Suga N (1977) Amplitude spectrum representation in the Dopplershifted-CF processing area of the auditory cortex of mustache bats. Science 196:64-67.
Suga N, Horikawa J (1986) Multiple time axes for representation of echo delays in the auditory cortex of the mustached bat. J Neurophysiol 55:776-805.

Suga N, Jen PH-S (1976) Disproportionate tonotopic representation for processing CF-FM sonar signals in the mustache bat auditory cortex. Science 194:542-544.

Suga N, Manabe T (1982) Neural basis of amplitude-spectrum representation in the auditory cortex of the mustached bat. J Neurophysiol 47:225-255.

Suga N, O'Neill WE (1979) Neural axis representing target range in the auditory cortex of the mustache bat. Science 206:351-353.

Suga N, Simmons JA, Jen PH-S (1975) Peripheral specializations for fine 'nalysis of Doppler-shifted echoes in the auditory system of the "CF-FM" bat Pteronotus parnellii. J Exp Biol 63:161-192.

Suga N, Niwa H, Taniguchi I (1983a) Representation of biosonar information in the auditory cortex of the mustached bat, with emphasis on representation of target velocity information. In: Advances in vertebrate neuroethology (Ewert JP, Capranica RR, Ingle DJ, eds), pp 829-867. New York: Plenum.

Suga N, O'Neill WE, Kujirai K, Manabe T (1983b) Specialization of "combination-sensitive" neurons for processing of complex biosonar signals in auditory cortex of the mustached bat. J Neurophysiol 49: $1573-1626$

Suga N, Niwa H, Taniguchi I, Margoliash D (1987) The pcrsonalized auditory cortex of the mustached bat: adaptation for echolocation. J Neurophysiol 58:643-654.

Sullivan WE (1982) Neural representation of target distance in auditory cortex of the echolocating bat Myotic lucifugus. J Neurophysiol 48:1011-1032.

Tanaka H, Wong D, Taniguchi I (1992) The influence of stimulus duration on the delay tuning of cortical neurons in the FM bat, Myotis lucifigus. J Comp Physiol A 171:29-40.

Tsuzuki K, Suga N (1988) Combination-sensitive neurons in the ventro-anterior area of the auditory cortex of the mustached bat. J Neurophysiol 60:1908-1923.

Wenstrup JJ, Winer JA (1987) Projections to the medial geniculate body form physiologically defined frequency representations of the mustached bat's inferior colliculus. Soc Ncurosci Abstr 13:324.

Winter P, Funkenstein HH (1973) The effect of species-specific vocalization on the discharge of auditory cortical cells in the awake squirrel monkey (Saimiri sciureus). Exp Brain Res 18:489-504.

Wollberg Z, Newman JD (1972) Auditory cortex of squirrel monkey: response patterns of single cells to species-specific vocalizations. Science 175:212-214.

Wong D, Maekawa M, Tanaka $H$ (in press) The effect of pulse repetition rate on the delay sensitivity of neurons in the auditory cortex of the FM bat, Myotis lucifigus. J Comp Physiol A, in press.

Zook JM, Leake PA (1989) Connections and frequency representation in the auditory brainstem of the mustache bat, Pteronotus parnellii. J Comp Neurol 290:243-261. 